\title{
Blended learning of radiology improves medical students' performance, satisfaction, and engagement
}

Adrien Vavasseur ${ }^{1}$, Fabrice Muscari ${ }^{2}$, Olivier Meyrignac ${ }^{1}$, Matthieu Nodot ${ }^{3}$, Fabrice Dedouit ${ }^{1,4}$, Paul Revel-Mouroz ${ }^{1}$, Louis Dercle ${ }^{5}$, Laura Rozenblum ${ }^{6}$, Lucy Wang ${ }^{7}$, Charlotte Maulat ${ }^{2}$, Hervé Rousseau', Philippe Otal', Laurent Dercle $e^{6,8,9}$ and Fatima-Zohra Mokrane ${ }^{1,7,8^{*}}$

\begin{abstract}
Purpose: To evaluate the impact of blended learning using a combination of educational resources (flipped classroom and short videos) on medical students' (MSs) for radiology learning.

Material and methods: A cohort of 353 MSs from 2015 to 2018 was prospectively evaluated. MSs were assigned to four groups (high, high-intermediate, low-intermediate, and low achievers) based on their results to a 20-MCQs performance evaluation referred to as the pretest. MSs had then free access to a self-paced course totalizing 61 videos based on abdominal imaging over a period of 3 months. Performance was evaluated using the change between posttest (the same 20 MCQs as pretest) and pretest results. Satisfaction was measured using a satisfaction survey with directed and spontaneous feedbacks. Engagement was graded according to audience retention and attendance on a web content management system.

Results: Performance change between pre and posttest was significantly different between the four categories (ANOVA, $P=10^{-9}$ ): low pretest achievers demonstrated the highest improvement (mean $\pm S D$, $+11.3 \pm 22.8$ points) while high pretest achievers showed a decrease in their posttest score (mean \pm SD, - $3.6 \pm 19$ points). Directed feedback collected from $73.3 \%$ of participants showed a 99\% of overall satisfaction. Spontaneous feedback showed that the concept of "pleasure in learning" was the most cited advantage, followed by "flexibility." Engagement increased over years and the number of views increased of 2.47-fold in 2 years.
\end{abstract}

Conclusion: Learning formats including new pedagogical concepts as blended learning, and current technologies allow improvement in medical student's performance, satisfaction, and engagement.

Keywords: Education, Radiology, Medical students, Blended learning

\footnotetext{
* Correspondence: mokrane_fatimazohra@yahoo.fr

${ }^{1}$ Service de Radiologie, CHU Toulouse-Rangueil, 1 avenue du Professeur Jean

Poulhès, TSA 50032, 31059 Toulouse, Cedex 9, France

${ }^{7}$ Columbia University, 116th St \& Broadway, New York, NY 10027, USA

Full list of author information is available at the end of the article
}

\section{SpringerOpen}

(c) The Author(s). 2020 Open Access This article is licensed under a Creative Commons Attribution 4.0 International License, which permits use, sharing, adaptation, distribution and reproduction in any medium or format, as long as you give appropriate credit to the original author(s) and the source, provide a link to the Creative Commons licence, and indicate if changes were made. The images or other third party material in this article are included in the article's Creative Commons licence, unless indicated otherwise in a credit line to the material. If material is not included in the article's Creative Commons licence and your intended use is not permitted by statutory regulation or exceeds the permitted use, you will need to obtain permission directly from the copyright holder. To view a copy of this licence, visit http://creativecommons.org/licenses/by/4.0/. 


\section{Key points}

- Low achievers take the best advantages from blended learning using video-based lectures.

- The use of a SPOC-based learning in a blended learning format was associated to a high face-to-face optional course attendance (86.1\%) highlighting thus the high students engagement.

- While directed feedback informs on students' overall satisfaction; spontaneous feedback provides a better understanding of the mechanisms that influence students' learning: Pleasure in learning is a major point in students' adherence to a new learning format.

\section{Introduction}

Past decades were highly impacted by rapid technological advancements and the introduction of information and communication technologies (ICT). This change led to permanent economic, social, and environmental changes, making nowadays society informationdriven and highly connected [1]. This radical shift in societal behavior also reflects in students' and teachers' behaviors and must be considered by current educational guidelines. New educational methods must be dynamic and responsive, in order to follow this evolving environment [2].

E-learning formats from massive open online courses (MOOC) to short private online courses (SPOC) are widely used in educational sciences, including medical education courses $[3,4]$. This paradigm shift in learning methods is a disruptive force because it challenges the tradition of lectures and shifts the educational experience in a learner-centered way. Health professions use SPOC technologies to improve the professional medical education of all medical students (MSs), ranging from undergraduate to postgraduates' trainees $[1,5-8]$. These design decisions are driven by economical, logistical, and other planning considerations. However, most of time, the decision is made based on the combined strength of different modalities for presenting course information [3]. Indeed, SPOCs' widespread acceptability has led to revised policies in educational standards, whatever are their types, ranging from fully online elements, i.e., computer-based learning environment without classroom components, to primary face-to-face learning with minor online elements [8].

Blended learning (BL) refers to a new educational strategy that integrates traditional face-to-face academic sessions with synchronous or asynchronous e-learning, to support and improve meaningful interactions between students, teachers, and electronic resources [9]. Most commonly, BL takes the advantages of both traditional courses and SPOC. Flipped classroom (FC) is one of the most challenging parts of $\mathrm{BL}$, where learners are introduced to new concepts via independent use of "prework" from SPOC [10]. This newly acquired knowledge is then applied and consolidated in an interactive classroom [11, 12]. This educational concept has the advantage of allowing students to engage the information of a discipline, at their own pace [13-15]. SPOC delivery platforms allow educators to create and deliver interactive courses in many forms as online resources, quizzes, virtual patients, or video-based lectures (VBL) [1618]. Many undergraduate MSs are auditors who engage primarily with videos while skipping over assessment problems, online discussions, and other interactive course components [19]. They, as young adults from Generation Z, make an extensive use of video in their daily lives [20]. The use of level-adapted VBLs is a new and innovative concept that meets the expectations of both teachers and students [21].

The importance of developing a formal medical imaging program has been demonstrated worldwide [22] Indeed, medical imaging teaching is often sporadic and taught irregularly during other medical modules rather than on its own [5]. Medical school educational programs, particularly radiology undergraduate training, are not standardized throughout Europe and USA [23-25]. The educational benefits of different types of radiology clerkships point at improvement in students' knowledge, interpretation skills, and students' satisfaction [26]. Additionally, there is a gap in knowledge of the exact benefits of these new educational tools compared to classical ones. Indeed, literature data lacks of reproducible and reliable tools to evaluate these techniques, and in the way to interpret results $[1,9,27]$. In this context, undergraduate medical imaging learning has been restructured in local university hospital using a combination of these new teaching concepts: blended learning based on a FC delivered in the form of VBLs and a face-to-face optional course. The purpose of this study is to decipher the impact of this teaching formula among three MS promotions. For this, three types of metrics were evaluatedperformance, satisfaction, and engagement-using both quantitative metrics (pre/posttest results' differences, students' attendance, audience retention, and key moments of audience overview) and qualitative assessment criteria (directed and spontaneous feedback).

\section{Material and methods Study design}

This single-site prospective study was conducted in a University Hospital Center between July 2015 and May 2018.

Figure 1 shows the study design. For three consecutive years, the study started the first day of abdominal rotation for 4th year undergraduate MSs (day 1). First, two 


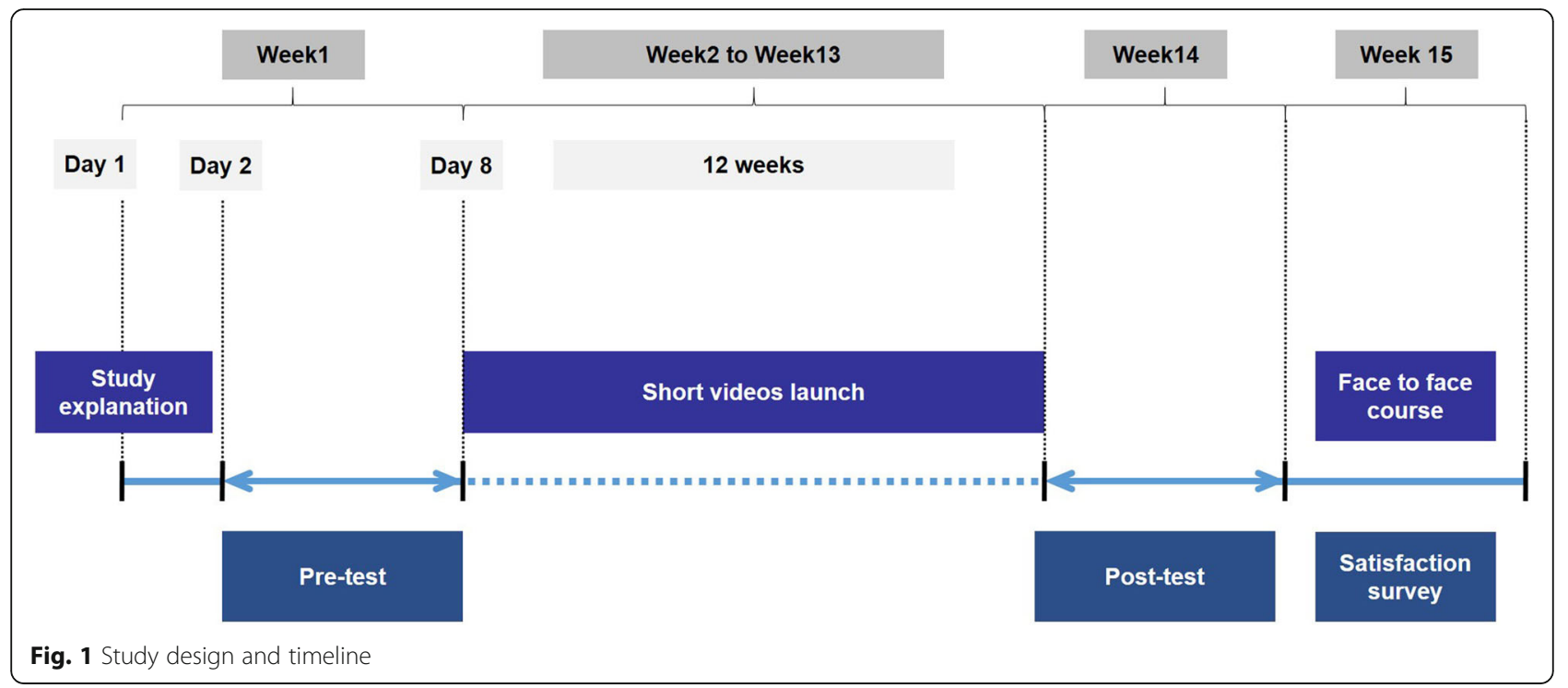

teachers (AV and FZM) presented the study to students during a short talk. Then, an initial online assessment (pretest) was launched and was available for 1 week (week 1). After pretest closing (week 2), VBLs were launched on a web content management system, and were available for 3 months. During week 14, a final online assessment (posttest) was launched.

All MSs who conducted the pre and posttests were included in the study. The final step of the study was a 2hour optional face-to-face course during the last week (week 15), in which test answers were discussed with students. At the end of this course, a facultative satisfaction survey was distributed to students.

Institutional Review Board approval was waived since the research involves no risk; the research did not involve use of identifiable private information, and did not adversely affect the rights and welfare of the subjects. Pedagogical faculty committee approved the study design.

\section{Pedagogical material creation (VBLs)}

Two experienced radiologists (AV and FZM) created short videos dedicated to this learning format. AV and FZM are experienced in both abdominal imaging (3 and 10 years of experience respectively) and in medical teaching ( 2 and 5 years of experience respectively). Several criteria were respected during VBL creation. First, all content was based on national medical imaging and gastroenterology MSs educational guidelines [28, 29]. Second, all included routine medical images originated from local PACS (picture archiving and communication system) and were strictly anonymized in compliance with French legislation. Finally, several form specificities were taken into consideration, according to international educational recommendations [30]: (i) video type used should be lectures with conceptual knowledge, produced using slide presentations with voice over; (ii) the requirement for video length is less than $6 \mathrm{mn}$, except if it contains medical imaging video loops (less than $15 \mathrm{mn}$ ); and (iii) videos must contain several pictures and imaging examples, video-motions with real imaging examples and continuous visual flow, along with extemporaneous speaking and extensive use of arrow pointer. All videos were reviewed by an expert radiologist, with 25 years of experience in abdominal imaging and 15 years of experience in medical teaching (PO).

\section{Content management system}

Videos were launched using a free open source web content management system [31] designed to provide educators and learners with a system dedicated to creating personalized learning environments. For each promotion, a dedicated moodle session, linked to our university website, was created. Online personal registration was mandatory for each MS.

\section{Evaluation}

Three educational parameters (performance, satisfaction, and engagement) and different types of metrics were used in this study in order to evaluate the obtained results quantitatively and qualitatively.

\section{Performance evaluation: pre/posttest evaluation}

The primary endpoint was to evaluate the impact of such a learning format on different types of students according to their performances, in order to know its impact on low achievers. For this, difference between pre and posttests results were calculated and compared in each student's category. Pre and posttests consisted of the same 20 multiple-choice questions (MCQs), focused 
on abdominal imaging. Tests were launched using a dedicated medical examination website [32]. The pre and posttests were scored on a 100-point scale distributed identically among the 20 MCQs. The mean overall improvement between the pre and posttests was calculated. Then, the overall population was divided into quartiles according to pretest scores (high, high-intermediate, low-intermediate, and low achievers) to evaluate the effectiveness of VBL according to pretest ranking.

\section{Satisfaction survey evaluation}

As a secondary endpoint, students' opinions on this learning format were collected. During the optional faceto-face course (week 15), a satisfaction survey composed of two parts was provided to all attendants.

The first part of the survey consisted of directed feedback. Answers to 13 questions were ranged using a 5point Likert scale. The rating scale for the overall course scoring was 1 = poor/strongly disagree, 2 = below average/disagree, 3 = average/neither agree or disagree, $4=$ above average/agree, and $5=$ excellent/strongly agree.

Then, as a part of a qualitative assessment, students were asked to give a spontaneous feedback by writing 2 to 3 sentences in answer to the question: "What is your overall perception of this learning format, with emphasis on positive points and points of improvement?". Answers were then collected as positive or negative concepts according to answers.

\section{Engagement evaluation}

The last secondary endpoint was to evaluate the engagement of students on the three consecutive promotions. Engagement indicators, extracted from Moodle platform statistics, were as follows: (i) student attendance with number of overall views, (ii) audience retention report for each video, and (iii) key moments of audience overview.

\section{Statistical analysis}

Qualitative variables were reported using counts and frequencies (percentages). Quantitative variables, following a Gaussian distribution in our study, are described by their means and standard deviations. Scores are expressed in absolute value and range from 0 (minimum) to 100 points (maximum). Students were divided into four quartiles (referred as [low, low-intermediate, high-intermediate, high] achievers) based on the pretest score. The efficacy of our teaching strategy was evaluated by computing differences between pretest and posttest. To this end, we have subtracted the absolute value of the pretest score from the absolute value of the posttest score. Pretest and posttest were also compared using Bland-Altman test. Chi-square test was used to compare scores between pre and posttests. Correlations between the pretest and posttest were assessed using Spearman's rho. ANOVA analysis was used to compare scores for each quartile. Student's evaluation of engagement was scored using the Likert scale (ranging from 1 to 5). Scores 4 and 5 using Likert scale (agree and strongly agree to the statement) were considered as "very satisfied." Statistical analyses were performed using the SPSS software (version 23.0, commercially available, IBM, Armonk, NY) and R software (version 3.6.0, open source).

\section{Results \\ Participants}

Four hundred thirty-three MSs, distributed through three consecutive promotions/years, were potentially eligible for this study. Among them, 353 (81.5\%) MSs performed both pre and posttests, and were included in the study accordingly (Table 1).

\section{Video-based lectures}

A total of 61 videos grouped in 17 major topics were recorded. Video lengths ranged from $1 \mathrm{~min} 17 \mathrm{~s}$ to $12 \mathrm{~min}$ $18 \mathrm{~s}$ (Table 2). The average length was $5 \mathrm{~min} 5 \mathrm{~s}$ and the total duration was $5 \mathrm{~h} 11 \mathrm{~min} 1 \mathrm{~s}$.

\section{Performance of pre and posttests}

The mean overall change between the pre and posttests was statistically significant $\left(+4.7\right.$ points, $\left.P=10^{-9}\right)$. There was a moderate correlation between pre and posttests $($ Rho $=0.30, P<0.05)$ (Table 3, Fig. 2$)$. The change in performance between the pretest and the posttest was significantly different between the four categories of achievers (ANOVA, $P=10^{-9}$ ): low pretest achievers demonstrated the highest improvement (mean: + 11.3 points, SD: \pm 22.8 points) while high pretest achievers showed a decrease in their posttest score (mean: - 3.6 points, SD: \pm 19 points) (Table 3, Fig. 3).

\section{Satisfaction survey evaluation}

Among the 304 students (86.1\% of included students) that attended to the optional face-to-face course, 259 completed the optional satisfaction survey $(73.3 \%$ of the included students, Table 1).

\section{Directed feedback}

Ninety-nine percent of MSs $(n=257)$ rated the overall learning experience as above average to excellent (Likert scores of 4 and 5). Ninety-five percent of them $(n=245)$ considered that they improved their knowledge using this method. Moreover, 99\% $(n=256)$ recommended this learning format to students in other medical imaging fields (Table 4).

\section{Spontaneous feedback}

Over 1525 spontaneous feedback reports were provided (average, 6 feedback per MSs). The concept of pleasure in learning was cited 750 times $(49.2 \%$ of overall feedback, 
Table 1 Overall selected medical students

\begin{tabular}{|c|c|c|c|c|}
\hline & $\begin{array}{l}\text { Promotion } 1 \text { (year 2015/ } \\
\text { 2016) }\end{array}$ & $\begin{array}{l}\text { Promotion } 2 \text { (year 2016/ } \\
\text { 2017) }\end{array}$ & $\begin{array}{l}\text { Promotion } 3 \text { (year 2017/ } \\
\text { 2018) }\end{array}$ & Total \\
\hline Overall (eligible students) & 148 & 149 & 136 & $433(100.0)$ \\
\hline Students performing the pretest & 146 & 140 & 132 & $418(96.5)$ \\
\hline Students performing the posttest & 133 & 118 & 111 & $362(83.6)$ \\
\hline $\begin{array}{l}\text { Students performing took both pre and } \\
\text { posttests* }\end{array}$ & 127 & 116 & 110 & $353(81.5)^{*}$ \\
\hline Students attending the optional course & 102 & 93 & 109 & $\begin{array}{l}304 \\
(86.1)^{* *}\end{array}$ \\
\hline Students answering the survey & 68 & 88 & 103 & $\begin{array}{l}259 \\
(73.3)^{* * *}\end{array}$ \\
\hline
\end{tabular}

Data are expressed in number of citations. Data in parentheses are percentages.

*Students included in the study. **Percentages are expressed regarding only included students

average of 3 times per student), describing the learning format as engaging (102 citations) and motivating (130 citations). This was followed by the concept of flexibility (314 citations), whereas the concept of performance enhancement and time optimization was cited only 200 times (Table 5).

Points needing improvement were cited 261 times, leaded by their request for more normal abdominal imaging (75 citations) and the possibility of access to material support (69 citations).

\section{Engagement evaluation}

In order to evaluate the students engagement in the new pedagogical method tested in this study, three different aspects of engagement were analyzed.

\section{Students' attendance}

Each student viewed 55.2 videos during the study. During promotion 1, the 127 MSs have viewed 3838 times the videos. This number of views has increased during the following promotions (6182 views by 116 MSs during promotion 2, and 9482 views by 110 MSs during promotion 3), showing thus a 2.47 -fold increase in the number of connections in 2 years (Fig. 4).

\section{Audience retention}

Over a 3-month period, the topic totalizing the most important views was "Appendicitis" (99 average views per video), followed by "Diverticulitis" (84 average views per video), and "Peritonitis" (83 average views per video). Topics focusing on

Table 2 Length of each video topic and student's attendance to videos during 3 months**

\begin{tabular}{|c|c|c|c|c|c|c|}
\hline VBLs' topics & Number of videos & Duration* & Overall & Promotion 1 & Promotion 2 & Promotion 3 \\
\hline Appendicitis & 6 & $4 \min 56 \mathrm{~s},[3 \min 1 \mathrm{~s}-8 \min 34 \mathrm{~s}]$ & 99 & 77 & 83 & 142 \\
\hline Diverticulitis & 2 & $7 \min 43 \mathrm{~s},[3 \min 7 \mathrm{~s}-12 \min 18 \mathrm{~s}]$ & 84 & 64 & 75 & 117 \\
\hline Peritonitis & 2 & $7 \min 58 \mathrm{~s}$, [5 $\min 56 \mathrm{~s}-9 \mathrm{~min}]$ & 83 & 67 & 75,5 & 110 \\
\hline Acute intestinal occlusion & 5 & $5 \min 37 \mathrm{~s},[3 \min 13 \mathrm{~s}-7 \min 31 \mathrm{~s}]$ & 76 & 65.2 & 69 & 95 \\
\hline Gastrointestinal bleeding & 2 & $4 \min 52 \mathrm{~s},[3 \min 51 \mathrm{~s}-5 \min 52 \mathrm{~s}]$ & 74 & 56 & 71 & 96.5 \\
\hline Colorectal tumors & 3 & $3 \min 35 s,[4 \min 28 s-8 \min 44 s]$ & 71 & 65.33 & 71.33 & 78 \\
\hline Esophagus tumors & 2 & $5 \min 16 s,[5 \min 12 s-5 \min 20 s]$ & 70 & 54 & 61 & 97 \\
\hline Inflammatory bowel disease & 3 & $4 \min 18 \mathrm{~s},[1 \min 56 \mathrm{~s}-6 \min 15 \mathrm{~s}]$ & 70 & 54 & 70.33 & 89 \\
\hline Acute abdominal pain & 2 & $4 \min 59 \mathrm{~s},[3 \min 3 s-6 \min 54 \mathrm{~s}]$ & 70 & 59 & 63.5 & 89 \\
\hline Acute and chronic pancreatitis & 7 & $5 \min 5 s,[1 \min 33 s-8 \min 36 s]$ & 69 & 48 & 52.5 & 112 \\
\hline Gastro duodenal ulcer & 1 & $6 \min 55 s$ & 68 & 57 & 60 & 89 \\
\hline Gallbladder disease & 4 & $4 \min 15 \mathrm{~s},[2 \min 18 \mathrm{~s}-5 \min 29 \mathrm{~s}]$ & 67 & 51 & 54.25 & 98 \\
\hline Gastric tumors & 1 & $7 \mathrm{~min} 31 \mathrm{~s}$ & 64 & 53 & 60 & 81 \\
\hline Hernias & 1 & $7 \mathrm{~min} 12 \mathrm{~s}$ & 64 & 48.33 & 62 & 84 \\
\hline Cirrhosis & 6 & $5 \min 30 \mathrm{~s},[2 \min 11 \mathrm{~s}-6 \min 16 \mathrm{~s}]$ & 56 & 48 & 53.4 & 68 \\
\hline Liver tumors & 12 & $4 \min 23 \mathrm{~s},[1 \min 17 \mathrm{~s}-6 \min 49 \mathrm{~s}]$ & 56 & 51.5 & 54.75 & 63 \\
\hline Pancreatic tumors & 2 & $6 \min 25 s,[6 \min 15 s-6 \min 34 s]$ & 46 & 35 & 37.5 & 67 \\
\hline
\end{tabular}

*Data are expressed in average [minimal duration-maximal duration].

**Average student's attendance during 3 months per video for each topic (week 2 to week 15) 
Table 3 Students' results and distribution according pretest results quartiles

\begin{tabular}{|c|c|c|c|c|}
\hline & $n$ & Pretest* & Posttest* & Delta overall* \\
\hline Overall & $353(100.0)$ & $73.0 \pm 12.1$ & $77.7 \pm 17.6$ & $+4.7 \pm 17.5$ \\
\hline \multicolumn{5}{|l|}{ Quartiles** } \\
\hline \multicolumn{5}{|l|}{ Quartile 1} \\
\hline Low achievers & $89(25.2)$ & $57.2 \pm 12.7$ & $65.6 \pm 24.6$ & $+11.3 \pm 22.8$ \\
\hline \multicolumn{5}{|l|}{ Quartile 2} \\
\hline Low-intermediate achievers & $88(24.9)$ & $70.7 \pm 7.7$ & $75.6 \pm 22.3$ & $+8.3 \pm 15.7$ \\
\hline \multicolumn{5}{|l|}{ Quartile 3} \\
\hline High-intermediate achievers & $90(25.5)$ & $76.8 \pm 8.4$ & $72.6 \pm 25$ & $1.66 \pm 14.4$ \\
\hline \multicolumn{5}{|l|}{ Quartile 4} \\
\hline High achievers & $86(24.4)$ & $85.7 \pm 9.9$ & $82.1 \pm 21.3$ & $-3.6 \pm 19$ \\
\hline$P$ values** & & NA & $P=10^{-7}$ & $P=10^{-9}$ \\
\hline
\end{tabular}

Data are expressed in number of students $(n)$, percentage, and mean \pm standard deviation. ${ }^{*}$ Scores are expressed in absolute value for a 100 -point test. ${ }^{*}$ ANOVA analysis for each quartile

chronic diseases such as cirrhosis, liver tumors, and pancreatic tumors were among the less consulted videos (Table 2).

\section{Audience overview: key moments}

Videos were most consulted at 2 key moments during the study: the beginning of the study (after VBLs launching and pretest) and before the posttest (Fig. 4).

\section{Discussion}

Learning medical practice requires young MSs to develop practical skills while increasing their knowledge, in order to be prepared for their future profession [33]. During the second cycle of medical studies, students learn how to interact not only with patients and their diseases, but also with the entire medical care team [34].

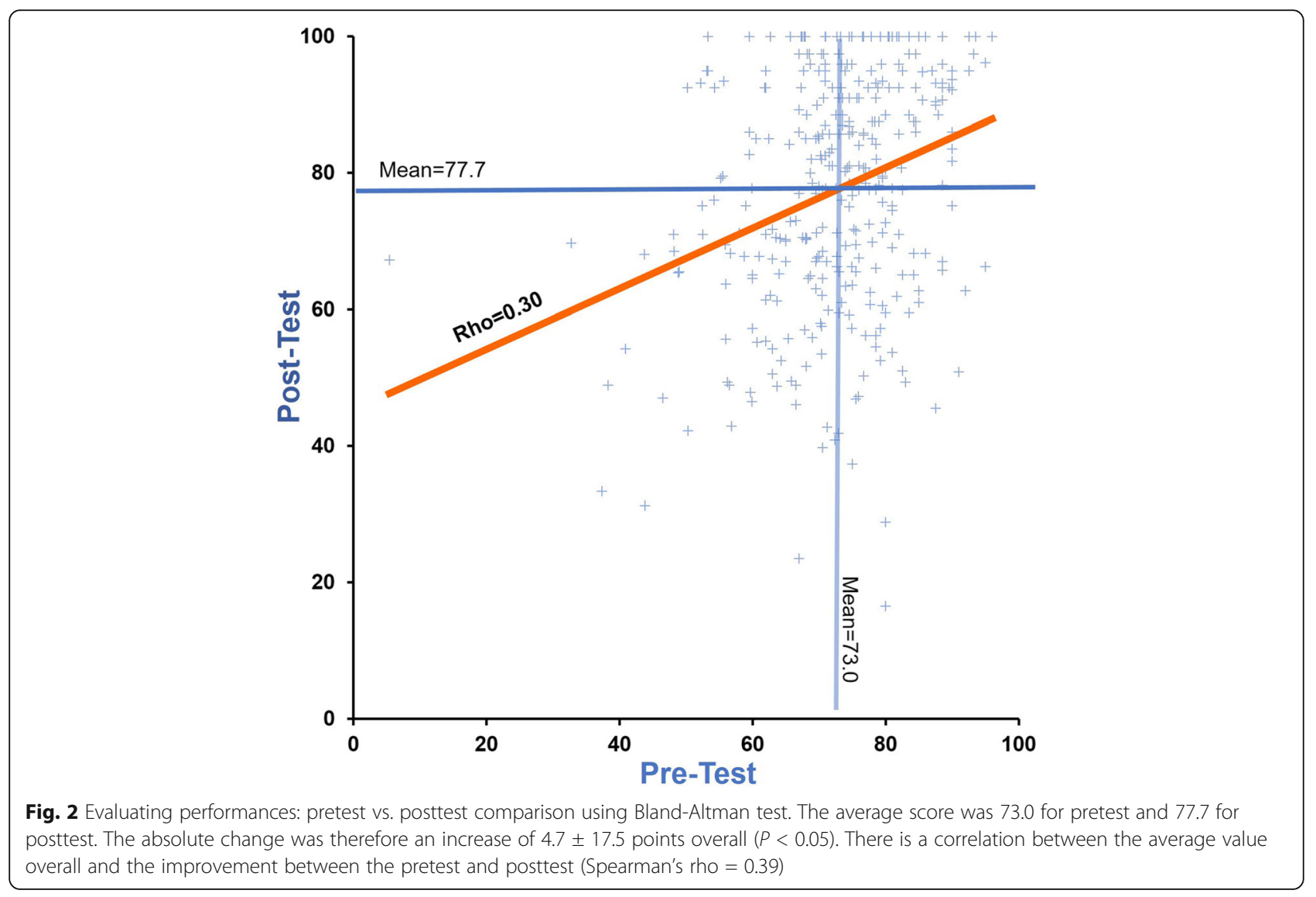




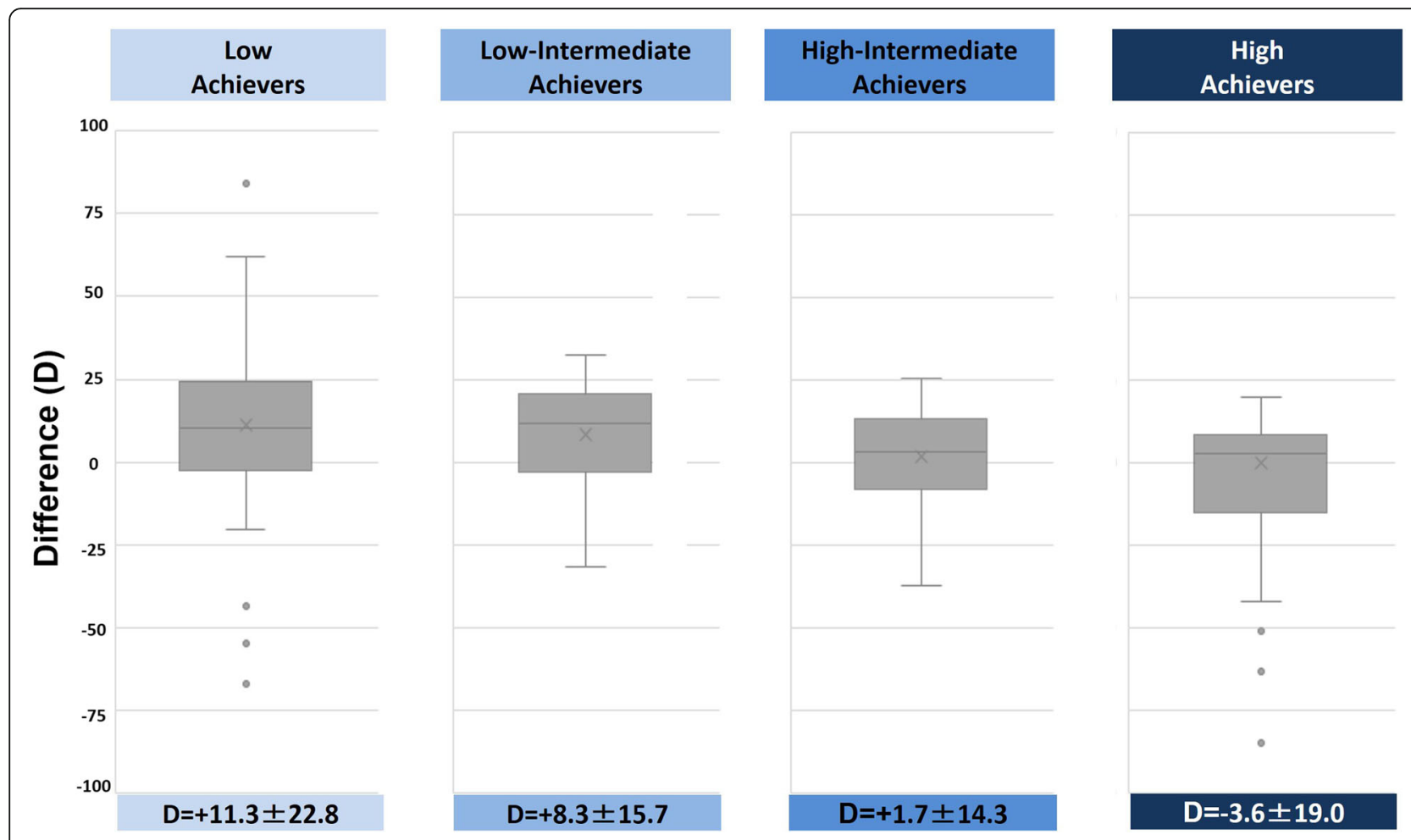

Fig. 3 Comparison of pre and posttest results according to groups defined by pretest scores. Difference $=$ (posttest score)-(pretest score). The highest improvement was observed in low achievers, 11.3 points $\pm 22.8\left(P=10^{-9}\right)$. Difference (D) is expressed in mean \pm standard deviation

Table 4 Directed feedback collected from students during the face-to-face optional course

\begin{tabular}{|c|c|c|c|c|}
\hline Satisfaction survey & Promotion $1^{*}$ & Promotion $2^{*}$ & Promotion $3^{*}$ & Total* \\
\hline \multicolumn{5}{|l|}{ Format evaluation } \\
\hline Did this learning format encourage you to study? & $66(97 \%)$ & $82(93 \%)$ & $93(90 \%)$ & $241(93 \%)$ \\
\hline Was the preliminary work reasonable? & $51(75 \%)$ & $82(93 \%)$ & $89(86 \%)$ & $222(86 \%)$ \\
\hline Do you consider the platform suitable? & $43(63 \%)$ & 81 (92\%) & 92 (89\%) & $225(87 \%)$ \\
\hline \multicolumn{5}{|l|}{ VBL evaluation } \\
\hline Are the videos easily accessible? & $63(93 \%)$ & $88(100 \%)$ & $102(99 \%)$ & $253(98 \%)$ \\
\hline Are the videos clear? & $68(100 \%)$ & $83(94 \%)$ & $101(98 \%)$ & $254(98 \%)$ \\
\hline Are the videos adapted to your level of knowledge? & $65(96 \%)$ & $84(95 \%)$ & $100(97 \%)$ & $249(96 \%)$ \\
\hline Are the videos of an adapted duration? & $65(96 \%)$ & $77(88 \%)$ & $94(91 \%)$ & $236(91 \%)$ \\
\hline Did you like the format of the videos? & $62(92 \%)$ & $86(98 \%)$ & $101(98 \%)$ & $249(96 \%)$ \\
\hline \multicolumn{5}{|l|}{ Tests evaluation } \\
\hline Did you improve using this learning method? & $64(94 \%)$ & $82(93 \%)$ & 99 (96\%) & $245(95 \%)$ \\
\hline Did you review reference books? & 67 (99\%) & $81(92 \%)$ & $91(88 \%)$ & $239(92 \%)$ \\
\hline Did you have the opportunity to self-evaluate? & $57(84 \%)$ & $77(88 \%)$ & $86(83 \%)$ & $220(85 \%)$ \\
\hline \multicolumn{5}{|l|}{ Global satisfaction } \\
\hline Are you satisfied with this learning format? & $68(100 \%)$ & $88(100 \%)$ & $101(98 \%)$ & $257(99 \%)$ \\
\hline \multicolumn{5}{|l|}{ Perspective } \\
\hline Would you recommend this learning format to other medical imaging fields? & $66(97 \%)$ & 87 (99\%) & $103(100 \%)$ & 256 (99\%) \\
\hline
\end{tabular}

*Represented student evaluation corresponds to scores 4 and 5 using Likert scale (agree and strongly agree to the statement) 
Table 5 Spontaneous feedback collected from students during the face-to-face optional course

\begin{tabular}{|c|c|c|c|c|}
\hline & $\begin{array}{l}\text { Overall } n= \\
259\end{array}$ & $\begin{array}{l}\text { Promotion } 1 n= \\
68\end{array}$ & $\begin{array}{l}\text { Promotion } 2 n= \\
88\end{array}$ & $\begin{array}{l}\text { Promotion } 3 n= \\
103\end{array}$ \\
\hline Concept of pleasure in learning & 750 & 216 & 234 & 300 \\
\hline Engaging & $102(38.6)$ & $38(55.8)$ & $24(27.3)$ & $40(38.8)$ \\
\hline Adapted format & $110(42.4)$ & $19(27.9)$ & $41(46.6)$ & $50(48.5)$ \\
\hline Motivating & $130(50.2)$ & $35(51.5)$ & $43(48.9)$ & $52(50.5)$ \\
\hline Didactic & $120(46.3)$ & $50(73.5)$ & $30(34.1)$ & $40(38.9)$ \\
\hline Clear & 119 (45.9) & $30(44.1)$ & $38(43.2)$ & $51(49,5)$ \\
\hline Correspond to their needs & $169(65.3)$ & $44(64.7)$ & $58(65.9)$ & $67(65.0)$ \\
\hline Concept of flexibility & 314 & 81 & 95 & 138 \\
\hline Enhances autonomy & $218(84.2)$ & $60(88.2)$ & $68(77.3)$ & $90(87.4)$ \\
\hline High availability & $96(37.0)$ & $21(17.6)$ & $27(30.7)$ & $48(46.6)$ \\
\hline Points needing improvement & 261 & 84 & 71 & 106 \\
\hline Extend the content to other imaging learning & $65(24.9)$ & $11(16.2)$ & $23(26.1)$ & $31(30.0)$ \\
\hline Technical adjustment (bad sound, inappropriate background color) & $52(20.0)$ & $18(26.5)$ & $12(16.9)$ & $22(21.4)$ \\
\hline Lack of courses dedicated to normal abdominal imaging & $75(28.6)$ & $6(8.8)$ & $27(38.0)$ & $42(40.8)$ \\
\hline Need for material support (PDF, downloaded videos) & $69(26.6)$ & $49(72.0)$ & $9(10.2)$ & $11(10.7)$ \\
\hline Concept of performance and time optimization & 200 & 72 & 55 & 73 \\
\hline Allows progression & $128(49.4)$ & $49(72.0)$ & $37(42.0)$ & $42(40.8)$ \\
\hline Time-saving & $72(27.8)$ & 23(33.8) & $18(20.5)$ & $31(30.1)$ \\
\hline
\end{tabular}

Data expressed in number of citations. Data in parentheses are percentages for each promotion

Additionally, the medical knowledge required for their future exercise is broad, covering fundamental knowledge, practical knowledge, particular gestures, and human contact [35]. For the last decades, new pedagogical techniques were tested in all medical fields, with the clear purpose of increasing students' knowledge and commitment [36, 37].

Comparison of pre and posttests results showed a significant overall improvement $\left(+4.7 \pm 17.5, P=P=10^{-9}\right)$.
Moreover, result analysis according to quartiles revealed that the low-achieving group (the lowest quartile) was most impacted by this learning. Indeed, while the vast majority of MSs improved in their posttest performances, low achievers showed the most important improvement. SPOCs delivered in the form of VBLs have important advantages in medical learning: speed of installation, availability, and no need for physical presence [38]. However, a successful blended learning combining several educational

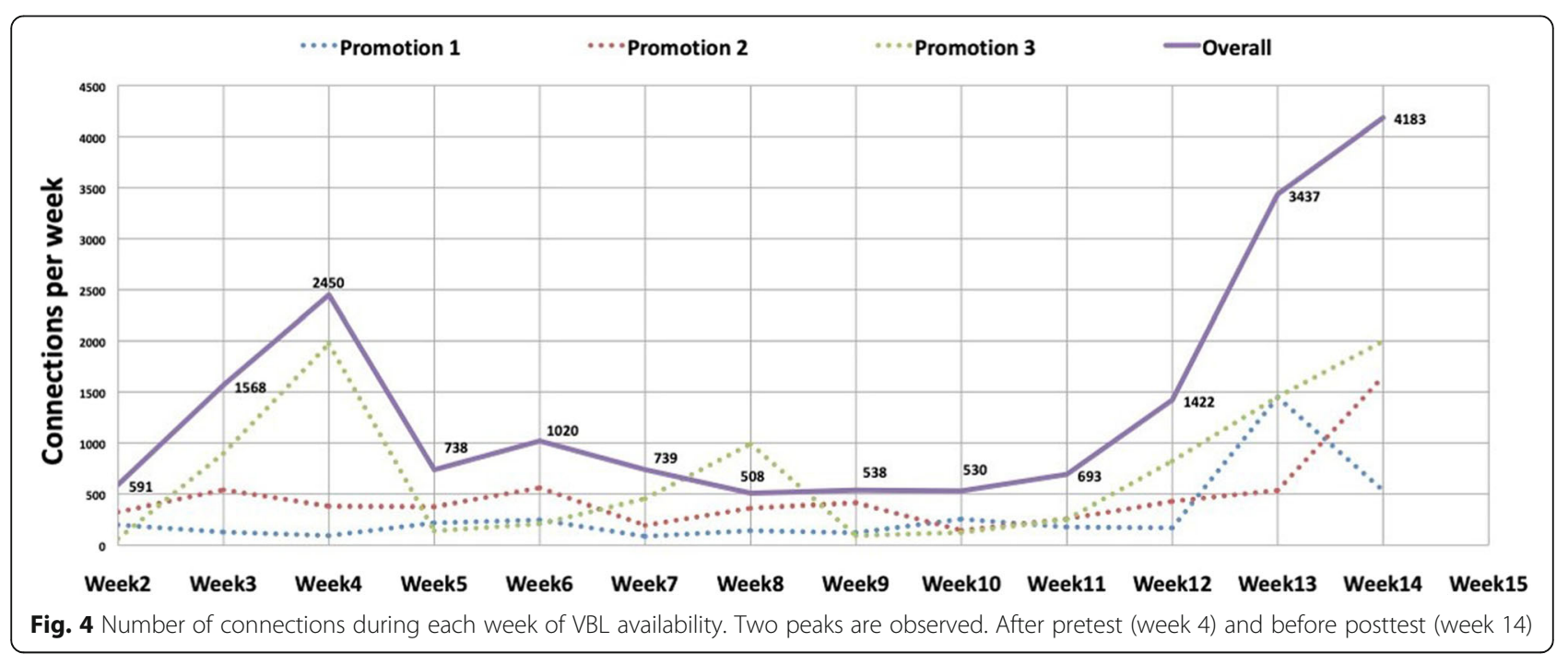


concepts requires that MSs adhere to VBLs and watch videos prior to the class. Metrics from this type of formula can be difficult to collect and interpret. In this study, quantitative results comparing pre and posttests were explored in a new manner. Low achievers appropriated VBL and their results have approached those of high achievers allowing for a homogenization in students' improvement. Social cognitive theory emphasizes self-efficacy as the primary driver of motivated action, and identifies cues that influence future self-efficacy and support self-regulated learning [39]. While high achievers are encouraged and highly praised, less academically inclined students are often marginalized [40]. Low achievers usually report more positively toward the use of video as a learning tool, perceived as more effective learning [12]. Regardless of their level, VBL allows every MS to progress. These benefits are more apparent in low achievers, as shown in this study. High achievers seem to be reinforced by their preset results, and probably focused on other learning tasks or other courses, adapting thus their own learning schedule.

The students were globally very satisfied regarding VBLs (99\% of satisfaction), as well as regarding the final face-to-face course. The pedagogical formula used in this study achieved high student engagement and satisfaction. Indeed, $86.1 \%$ of included students attended to the optional face-to-face course, showing their interest in keeping a close contact with teachers. E-learning has a major impact on Generation Z students [41]. Its use in teaching radiology for MSs is widely documented, with global student and teacher satisfaction as well as results improvement [39, 40, 42, 43]. The objective is a clear trend toward a highly interactive and self-directed learning environment to support the concept of life-long independent learners [44]. However, the community of teachers has difficulties finding scientific evidence on how they should design their teaching $[45,46]$.

FC presents benefits of both e-learning and traditional teaching, allowing for a greater educational impact with less instructional time [42, 47]. Students can access learning materials at their own pace [48]. In medical imaging learning, this technique seems to be more effective than traditional learning, but requires greater rigor and commitment from students [27], and a high quality of online imaging content and quizzes [49]. In this study, the overall rating of the learning format by students was high ( $99 \%$ of level of satisfaction), despite the higher required commitment. This is explained by the fact that VBLs were perceived as "engaging" by students. Indeed, pleasure in learning is a key concept for e-learning. This concept represents 750 citations in the spontaneous feedback collected by the satisfaction survey in this study. Furthermore, motivation is a fundamental criterion in online education. The absence of interaction with teachers makes it difficult to learn alone remotely, especially for complex courses and requires the establishment of more and longer seminars [50]. In our study, students clearly expressed the increase in their motivation related to VBLs. Motivation due to impending deadlines is important, as seen with the peak in student engagement and video connection peak before the posttest. Indeed, induced motivation results in a more extensive use of VBL by MSs than self-determined motivation [51]. However, further studies with true video engagement quantification will help to better understand students' expectations.

In this study, there is a clear value in new educational technologies with a blended learning format combining e-learning and a face-to-face classical course, in which students can be in direct interaction with their teachers. Indeed, students improved their results, adhered to the learning concept, and attended to the face-to-face course. In current literature data, there is a lack of extensive and quantitative studies in medical learning in highlighting the real impact of e-learning $[52,53]$. Although there are strong pedagogical arguments that favor a blended learning approach, literature on the relative effectiveness of blended versus traditional learning approaches is mixed. Students' attendance and adherence to BL seem to be higher when compared to a classical format; this type of teaching favors long-term memorization and knowledge assimilation $[13-15,54$, 55], without impact on outcomes [56-58].

VBLs achieving the highest view counts are those concerning emergency topics (appendicitis and diverticulitis) that may be applicable to a broader range of medical learners. The ability to access the educational content immediately, regardless of location, appears to be a major concern for students. Radiology is becoming increasingly important in the diagnostic and therapeutic management of patients. Indeed, radiology education does not only concern future radiologists but also any future doctors. Medical practitioners need more and more imaging knowledge upon time and technologies [59]. The development of mobile-learning, by the implementation of videos on smartphone applications, makes it possible to overcome this concern while using an innovative learning tool that is appreciated by the students [60-62].

Educational videos are widely used in educational science as a dissemination tool for web-based training [63]. The effective use of videos as a teaching tool is enhanced when teachers consider how they should manage the cognitive load of videos, maximize student engagement with videos, and promote active learning from video [64]. The choice of using short videos in this work (average length of $5 \mathrm{~min} 5 \mathrm{~s}$ ) was based on the fact that engagement is highly associated with video length [65]. The main advantage of the VBL format is time and place 
flexibility for potentially overwhelmed learners. Our choice of video production style was driven by our main purpose, which was to provide massive real-life imaging examples of both normal and pathological imaging findings in abdominal imaging [66]. Slide presentations with voice over production style showed high engagement in this study ( $96 \%$ of satisfaction).

However, this study has some limitations. First, there is an inclusion bias: $18 \%$ of MSs did not perform pre and posttests (80/433) and only 259 students over the 353 included (73.3\%) answered the satisfaction survey. This is mainly due to the fact that these tests were not included in the final note that validates the abdominal rotation. In order to reduce the "missing" students' rates, several reminders were introduced during the entire rotation, in order to encourage the students to perform the whole experience.

Further studies, in which true video engagement quantification is measured, and comparison to classical faceto-face courses will help to better understand students' needs and behaviors regarding new technologies.

\section{Conclusion}

The blended learning format used in this study, combining short video-based lectures, as flipped classroom material, with a face-to-face course and pre and posttests showed high results regarding students' performance, satisfaction, and engagement. This learning method has allowed students to progress by improving their motivation and pleasure in learning. This study shows that several metrics can be used to measure students' improvement, and furthermore, the reasons for the success of a specific learning format, in a conceptual manner.

\section{Abbreviations}

BL: Blended learning; FC: Flipped classroom; MCQ: Multiple-choice questions; MS: Medical students; SPOC: Small Private Online Course; VBL: Video-based lectures

\section{Acknowledgements}

None

\section{Authors' contributions}

$A V$, online courses preparation, data collection, manuscript writing. FM: study design, manuscript edition. OM: manuscript edition. MN: technical support to online courses. FD: manuscript edition. PRM: manuscript edition. Louis D: manuscript writing. LR: manuscript edition. LW manuscript language edition. CM: manuscript writing. HR: manuscript edition. PO: online courses preparation, manuscript edition. LD: study design, data analysis, statistical analysis, edition.. FZM: study design, online courses preparation, data collection, manuscript writing, and edition. All authors read and approved the final manuscript.

\section{Funding \\ None}

\section{Availability of data and materials}

All data and materials can be available online.

\section{Consent for publication}

All authors confirm their consent for publication.

\section{Competing interests}

None

\section{Author details}

${ }^{1}$ Service de Radiologie, CHU Toulouse-Rangueil, 1 avenue du Professeur Jean Poulhès, TSA 50032, 31059 Toulouse, Cedex 9, France. ${ }^{2}$ Service de Chirurgie digestive, CHU Toulouse-Rangueil, 1 avenue du Professeur Jean Poulhès, TSA 50032, 31059 Toulouse, Cedex 9, France. Ingénieur en pédagogie, service d'appui pédagogique, Université Toulouse III-Paul Sabatier, Route de Narbonne, 31300 Toulouse, France. ${ }^{4}$ Service de médecine légale, CHU Toulouse-Rangueil, 1 avenue du Professeur Jean Poulhès, TSA 50032, 31059 Toulouse, Cedex 9 ${ }^{\prime \prime}$ France. ${ }^{5}$ Faculté de pharmacie de Châtenay-Malabry, 5 Rue Jean-Baptiste Clément, 92290 Châtenay-Malabry, France. ${ }^{6}$ Sorbonne Université, Service de Médecine Nucléaire, AP-HP, Hôpital La Pitié-Salpêtrière, 75013 Paris, France. ${ }^{7}$ Columbia University, 116th St \& Broadway, New York, NY 10027, USA. ${ }^{8}$ New York Presbyterian Hospital, Columbia University, New York City, NY, USA. ${ }^{9}$ Gustave Roussy Institute, UMR1015, Université Paris-Saclay, F-94805 Villejuif, France.

Received: 18 November 2019 Accepted: 31 March 2020 Published online: 28 April 2020

\section{References}

1. Kavadella A, Tsiklakis K, Vougiouklakis G, Lionarakis A Evaluation of a blended learning course for teaching oral radiology to undergraduate dental students. European Journal of Dental Education 16(1):e88-e95

2. Mattheos N, Stefanovic N, Apse P, Attstrom R, Buchanan J, Brown P et al (2008) Potential of information technology in dental education. Eur J Dent Educ. 12(Suppl 1):85-92

3. Osguthorpe RT, Graham CR (2003) Blended learning environments: definitions and directions. Quarterly Review of Distance Education. 4(3): 227-233

4. Bozkurt A, Akgun-Ozbek E, Yilmazel S, Erdogdu E, Ucar H, Guler E, et al. Trends in distance education research: a content analysis of journals 20092013. The International Review of Research in Open and Distributed Learning [Internet]. 2015 [cited 2018];16(1). Available from: http://www. irrodl.org/index.php/irrodl/article/view/1953

5. Kourdioukova EV, Valcke M, Derese A, Verstraete KL (2011) Analysis of radiology education in undergraduate medical doctors training in Europe. Eur J Radiol. 78(3):309-318

6. Kiviniemi MT (2014) Effects of a blended learning approach on student outcomes in a graduate-level public health course. BMC Med Educ. 14:47

7. Harder B (2013) Are MOOCs the future of medical education? BMJ. 346: f2666

8. Mehta NB, Hull AL, Young JB, Stoller JK (2013) Just imagine: new paradigms for medical education. Acad Med. 88(10):1418-1423

9. Vásquez A, Palazuelos G, Pinzon BA, Romero J. Blended learning in radiology: evaluation of a nationwide training program on breast imaging. Journal of the American College of Radiology. 2018;15(3, Part A):458-462.

10. Graham CR, Woodfield W, Harrison JB (2013) A framework for institutional adoption and implementation of blended learning in higher education. Internet and Higher Education. 18:4-14

11. Prober CG, Khan S (2013) Medical education reimagined: a call to action. Acad Med. 88(10):1407-1410

12. Nouri J (2016) The flipped classroom: for active, effective and increased learning - especially for low achievers. Int J Educ Technol High Educ. 13(1):33

13. Means B, Toyama Y, Murphy R, Bakia M, Jones K. Evaluation of evidencebased practices in online learning: a meta-analysis and review of online learning studies [Internet]. US Department of Education; 2009 [cited 2017]. Available from: https://eric.ed.gov/?id = ED505824

14. Freeman S, Eddy SL, McDonough M, Smith MK, Okoroafor N, Jordt $\mathrm{H}$ et al (2014) Active learning increases student performance in science, engineering, and mathematics. Proc Natl Acad Sci U S A. 111(23):8410-8415

15. Wieman CE (2014) Large-scale comparison of science teaching methods sends clear message. Proc Natl Acad Sci U S A. 111(23):8319-8320

16. Kononowicz AA, Berman AH, Stathakarou N, McGrath C, Bartyński T, Nowakowski $\mathrm{P}$, et al. Virtual patients in a behavioral medicine massive open 
online course (MOOC): a case-based analysis of technical capacity and use navigation pathways. JMIR Med Educ [Internet]. 2015 [cited 2018];1(2). Available from: https://www.ncbi.nlm.nih.gov/pmc/articles/PMC5041343/

17. Stathakarou N, Zary N, Kononowicz AA (2014) Beyond XMOOCs in healthcare education: study of the feasibility in integrating virtual patient systems and MOOC platforms. PeerJ. 2:e672

18. Robinson R (2016) Delivering a medical school elective with massive open online course (MOOC) technology. PeerJ. 4:e2343

19. Kizilcec RF, Piech C, Schneider E. Deconstructing disengagement: analyzing learner subpopulations in massive open online courses. In: Proceedings of the Third International Conference on Learning Analytics and Knowledge [Internet]. New York, NY, USA: ACM; 2013 [cited 2018]. p. 170-9. (LAK '13). Available from: http://doi.acm.org/10.1145/2460296.2460330

20. Vogelsang M, Rockenbauch K, Wrigge H, Heinke W, Hempel G. Medical education for "Generation Z": everything online?! - an analysis of internetbased media use by teachers in medicine. GMS J Med Educ [Internet]. 2018 [cited 2019];35(2). Available from: https://www.ncbi.n/m.nih.gov/pmc/ articles/PMC6022581/

21. Dufour J-C, Emeric A, Giorgi R (2016) Interactive videos within an e-learning context. Stud Health Technol Inform. 221:117

22. Gunderman RB, Siddiqui AR, Heitkamp DE, Kipfer HD (2003) The vital role of radiology in the medical school curriculum. AJR Am J Roentgenol. 180(5): 1239-1242

23. Barzansky B, Etzel SI (2004) Educational programs in US medical schools, 20032004. JAMA: Journal of the American Medical Association. 292(9):1025-103

24. Jafri NF, Wu P, Stanfield L, Slanetz PJ (2008) Use of radiologic imaging to enhance physical diagnosis instruction in the preclinical curriculum. Acad Radiol. 15(7):942-947

25. Linaker KL (2015) Radiology undergraduate and resident curricula: a narrative review of the literature. J Chiropr Humanit. 22(1):1-8

26. Relyea-Chew A, Chew FS (2007) Dedicated core clerkship in radiology for medical students development, implementation, evaluation, and comparison with distributed clerkship. Acad Radiol. 14(9):1127-1136

27. Spanjers IA, Könings KD, Leppink J, Verstegen DM, de Jong N, Czabanowska $K$ et al (2015) The promised land of blended learning: quizzes as a moderator. Educational Research Review. 15:59-74

28. Abrégé d'Hépato-gastro-entérologie et de chirurgie digestive | SNFGE.org Société savante médicale française d'hépato-gastroentérologie et d'oncologie digestive [Internet]. [cited 2018]. Available from: https://www. snfge.org/content/abrege-dhepato-gastro-enterologie-et-de-chirurgiedigestive

29. Référentiel Imagerie / CERF - Collège des Enseignants en Radiologie de France [Internet]. [cited 2018]. Available from: http://cerf.radiologie.fr/ enseignement/etudiants-medecine-preparation-ecni/r\%C3\%A9f\%C3\% A9rentiel-imagerie

30. Zoghbi V, Caskey RC, Dumon KR, Soegaard Ballester JM, Brooks AD, Morris JB et al (2018) "How To" videos improve residents performance of essential perioperative electronic medical records and clinical tasks. J Surg Educ. 75(2):489-496

31. Plateforme pédagogique de l'université Paul Sabatier - UT3 [Internet]. [cited 2020]. Available from: https://moodle.univ-tlse3.fr/

32. Accueil | Info SIDE-Santé [Internet]. [cited 2020]. Available from: https://infosides.uness.fr/

33. Audétat MC, Rieder A, Sommer J (2017) Teaching clinical reasoning is more like detective work than you might imagine. Revue medicale suisse. 13(562):981

34. Makoul G, Altman M (2002) Early assessment of medical students' clinical skills. Academic Medicine. 77(11):1156

35. Mukohara K, Kitamura K, Wakabayashi H, Abe K, Sato J, Ban N (2004) Evaluation of a communication skills seminar for students in a Japanese medical school: a non-randomized controlled study. BMC medical education. 4(1):24

36. Pfeiffer CA, Ardolino AJ, Madray H (2001) The impact of a curriculum renewal project on students' performances on a fourth-year clinical skills assessment. Academic Medicine. 76(2):173-175

37. Norman G (2003) RCT= results confounded and trivial: the perils of grand educational experiments. Medical education. 37(7):582-584

38. Cook DA, Levinson AJ, Garside S, Dupras DM, Erwin PJ, Montori VM (2008) Internet-based learning in the health professions: a meta-analysis. JAMA. 300(10):1181-1196
39. Cook DA, Artino AR (2016) Motivation to learn: an overview of contemporary theories. Med Educ. 50(10):997-1014

40. Dompnier B, Darnon C, Meier E, Brandner C, Smeding A, Butera F (2015) Improving low achievers' academic performance at university by changing the social value of mastery goals. American Educational Research Journal. 52(4):720-749

41. Zhang D, Nunamaker JF (2003) Powering e-learning in the new millennium: an overview of e-learning and enabling technology. Information systems frontiers. 5(2):207-218

42. Belfi LM, Bartolotta RJ, Giambrone AE, Davi C, Min RJ (2015) "Flipping" the introductory clerkship in radiology: impact on medical student performance and perceptions. Academic radiology. 22(6):794-801

43. Moreira IC, Ventura SR, Ramos I, Rodrigues PP (2015) Development and assessment of an e-learning course on breast imaging for radiographers: a stratified randomized controlled trial. Journal of medical Internet research 17(1)

44. Zafar S, Safdar S, Zafar AN (2014) Evaluation of use of e-learning in undergraduate radiology education: a review. Eur J Radiol. 83(12):2277-2287

45. Gunderman RB, Ballenger Z (2014) The golden rule of education. Academic Radiology. 21(8):1078-1079

46. Fenderson BA (2005) Strategies for teaching pathology to graduate students and allied health professionals. Human pathology. 36(2):146-153

47. Wiley: The handbook of blended learning: global perspectives, local designs - Curtis J. Bonk, Charles R. Graham, Jay Cross, et al [Internet]. [cited 2017]. Available from: http://www.wiley.com/WileyCDA/WileyTitle/productCd0787977586.html

48. Foertsch J, Moses G, Strikwerda J, Litzkow M (2002) Reversing the lecture/ homework paradigm using eTEACH ${ }^{\oplus}$ web-based streaming video software. Journal of Engineering Education. 91(3):267-274

49. Howlett D, Vincent T, Watson G, Owens E, Webb R, Gainsborough N et al (2011) Blending online techniques with traditional face to face teaching methods to deliver final year undergraduate radiology learning content. European journal of radiology. 78(3):334-341

50. Mayer B, Ring C, Muche R, Rothenbacher D, Schmidt-Strals sburger U, others. Creating a blended learning module in an online master study programme in oncology. Education for Health. 2015;28(1):101. https://doi. org/10.4103/1357-6283.161951

51. Mahnken AH, Baumann M, Meister M, Schmitt V, Fischer MR (2011) Blended learning in radiology: is self-determined learning really more effective? European Journal of Radiology. 78(3):384-387

52. Holmström A, Ahonen S-M (2016) Radiography students' learning: a literature review. Radiologic technology. 87(4):371-379

53. Zafar S, Safdar S, Zafar AN (2014) Evaluation of use of e-learning in undergraduate radiology education: a review. European journal of radiology. 83(12):2277-2287

54. Dowling§ C, Godfrey§ JM, Gyles N. Do hybrid flexible delivery teaching methods improve accounting students' learning outcomes? Accounting Education. 2003:12(4):373-91.

55. Lau KHV, Farooque P, Leydon G, Schwartz ML, Sadler RM, Moeller JJ (2018) Using learning analytics to evaluate a video-based lecture series. Medical Teacher. 40(1):91-98

56. Riddell J, Jhun P, Fung C-C, Comes J, Sawtelle S, Tabatabai R et al (2017) Does the flipped classroom improve learning in graduate medical education? Journal of Graduate Medical Education. 9(4):491-496

57. Anderson K, May FA (2010) Does the method of instruction matter? An experimental examination of information literacy instruction in the online, blended, and face-to-face classrooms. Journal of Academic Librarianship. 36(6):495-500

58. Bains M, Reynolds PA, McDonald F, Sherriff M (2011) Effectiveness and acceptability of face-to-face, blended and e-learning: a randomised trial of orthodontic undergraduates. Eur J Dent Educ. 15(2):110-117

59. Nyhsen CM, Lawson C, Higginson J (2011) Radiology teaching for junior doctors: their expectations, preferences and suggestions for improvement. Insights Imaging. 2(3):261-266

60. Boruff JT, Storie D (2014) Mobile devices in medicine: a survey of how medical students, residents, and faculty use smartphones and other mobile devices to find information. Journal of the Medical Library Association: JMLA. 102(1):22

61. Schulz P, Sagheb K, Affeldt H, Klumpp H, Taylor K, Walter C, et al. Acceptance of e-learning devices by dental students. Medicine 20. 2013;2(2)

62. Walsh K (2015) Mobile learning in medical education. Ethiopian journal of health sciences. 25(4):363-366 
63. Stockwell BR, Stockwell MS, Cennamo M, Jiang E (2015) Blended learning improves science education. Cell. 162(5):933-936

64. Brame CJ (2016) Effective educational videos: principles and guidelines for maximizing student learning from video content. CBE-Life Sciences

Education 15(4):es6

65. Isaacs A, Nisly S (2016) Walton A. Student-generated e-learning for clinical education, Clin Teach

66. Guo PJ, Kim J, Rubin R. How video production affects student engagement: an empirical study of mooc videos. Proceedings of the first ACM

conference on Learning @ scale conference. 2014. p. 41-50. https://doi.org/ 10.1145/2556325.2566239.

\section{Publisher's Note}

Springer Nature remains neutral with regard to jurisdictional claims in published maps and institutional affiliations.

\section{Submit your manuscript to a SpringerOpen ${ }^{\circ}$ journal and benefit from:}

- Convenient online submission

- Rigorous peer review

- Open access: articles freely available online

- High visibility within the field

- Retaining the copyright to your article

Submit your next manuscript at $\boldsymbol{\nabla}$ springeropen.com 